\title{
Modeling Maternal Risk Factors Affecting Low Birth Weight Among Infants in Kenya
}

\author{
Nancy Wairimu Gathimba ${ }^{1, *}$, Anthony Wanjoya ${ }^{1}$, George Kipruto Kiplagat ${ }^{1}$, Levi Mbugua ${ }^{2}$, \\ Koima Kibiwott ${ }^{3}$ \\ ${ }^{1}$ Department of Statistics and Acturial Sciences, Jomo Kenyatta University of Agriculture and Technology, Nairobi, Kenya \\ ${ }^{2}$ Department of Statistics and Acturial Sciences, Technical University, Nairobi, Kenya \\ ${ }^{3}$ Department of Statistics and Acturial Sciences, Kabarak University, Nakuru, Kenya \\ Email address: \\ wairimuigai@yahoo.com (N.W. Gathimba), awanjoya@gmail.com (A. Wanjoya), gtaleinah.g4@gmail.com (G. K. Kiplagat), \\ crekfound@yahoo.com (L. Mbugua),bkoima@yahoo.com (K. Kibiwott) \\ *Corresponding author
}

\section{To cite this article:}

Nancy Wairimu Gathimba, Anthony Wanjoya, George Kipruto Kiplagat, Levi Mbugua, Koima Kibiwott. Modeling Maternal Risk Factors Affecting Low Birth Weight Among Infants in Kenya. American Journal of Theoretical and Applied Statistics. Vol. 6, No. 1, 2017, pp. $22-31$. doi: $10.11648 /$ j.ajtas.20170601.13

Received: December 8, 2016; Accepted: December 20, 2016; Published: January 18, 2017

\begin{abstract}
The strong association of birth weight with infant mortality is the main focus of birth weight research, with the assumption that birth weight is a major determinant of infant survival. Studies on factors of low birth weight in Kenya have neglected the flexible approach of using smooth functions for some covariates in models. Such flexible approach reveals detailed relationship of covariates with the response. The study sought to investigate risk factors of low birth weight in Kenya by assuming a flexible approach for continuous covariates and geographical random effect. The study used semi parametric models to flexibly model the effects of selected covariates and spatial effects. Our spatial analysis is based on a flexible geo-additive model using the provinces as the geographic unit of analysis, which allows to separate smooth structured spatial effects from random effect. A Gaussian model for birth weight in grams and a binary logistic model for the binary outcome were fitted. Continuous covariates was modeled by the penalized (p) splines and spatial effects was smoothed by the two dimensional p-spline. The specific objectives of the study was to investigate factors of low birth weight in Kenya by taking into account the hierarchical nature of child birth weight factors using a Bayesian hierarchical model. The study used secondary data from Kenya 2014 demographic and health survey (KDHS) data. The study found that child birth order, mother weight and height are significant predictors of birth weight. Secondary education for mother, birth order categories 2-3 and 4-5, wealth index of richer family and mother height were significant predictors of child size at birth. The area associated with low birth weight was North Eastern and areas with increased risk to less than average size at birth were Central and Eastern. The study found support for the flexible modeling of some covariates that clearly have nonlinear influences. Nevertheless there was no strong support for inclusion of geographical spatial analysis. The spatial patterns and the maps generated could be used for targeting development efforts at a glance. These findings have important implications for targeting policy as well as the search for left-out variables that might account for these residual spatial patterns.
\end{abstract}

Keywords: Low Birth Weight, Geo-additive Models, Spatial Effect, Penalised Splines, Semi Parametric Bayesian Analysis

\section{Introduction}

Background of the study

The birth weight of an infant is highly significant in two important aspects. First, it is strongly conditioned by the health and nutritional status of the mother and second, it is one of the most important determinants of the chances of the newborn to survive and experience healthy growth and development. According to World Health Organization around 3.3 million babies die within their first month of life every year and the proportion of neonatal deaths has increased in all regions of the world and is currently estimated at $41 \%$ [26], [27]. $90 \%$ of these deaths occur in low and middle 
income countries and a third of all neonatal deaths occur in sub Saharan Africa. Low birth weight continues to be a significant public health problem globally and is associated with a range of both short- and long-term consequences. Overall, it is estimated that $15 \%$ to $20 \%$ of all births worldwide are Low Birth Weight, representing more than 20 million births a year. In 2012, the World Health Assembly Resolution 65.6 endorsed a Comprehensive implementation plan on maternal, infant and young child nutrition, which specified six global nutrition targets for 2025, Which include: $40 \%$ reduction in the number of children under-five who are stunted, $50 \%$ reduction of anaemia in women of reproductive age, $30 \%$ reduction in low birth weight, No increase in childhood overweight, Increasing the rate of exclusive breastfeeding in the first six months up to at least $50 \%$ and maintaining childhood wastage to less than 5\%; [17]. This resolution covers the third target: a $30 \%$ reduction of low birth weight. The purpose of this resolution is to increase attention to, investment in, and action for a set of cost-effective interventions and policies that can help Member States and their partners in reducing rates of low birth weight. The goal is to achieve a $30 \%$ reduction of the number of infants born with a weight lower than $2500 \mathrm{~g}$ by the year 2025. This would translate into a $3.9 \%$ relative reduction per year between 2012 and 2025 and a reduction from approximately 20 million to about 14 million infants with low weight at birth. The 48 hours immediately following birth is the most crucial period for newborn survival. This is when the mother and child should receive follow-up care to prevent and treat illness. Prior to birth, the mother can increase her child's chance of survival and good health by attending antenatal care consultations, being immunized against tetanus, and avoiding smoking and use of alcohol. The prevalence of Low Birth Weight in Kenya is estimated to be 11 percent by World Health Organization and United Nations Children's Fund. The Kenya Demographic Health Survey of 2009 estimates Low Birth Weight to be 6 percent. Low Birth Weight is a major cause of morbidity and mortality in Kenya. [8] The current trends of infant and under five mortality rates in Kenya are declining. Child mortality has declined by 36 percent from 115 per 1000 in 2003 to 74 deaths per 1000 in 2008; [7], While infant mortality has declined by 32 percent from 77 deaths per 1000 in the 2003 to 52 deaths per 1000 in the 2008. Neonatal mortality changed from 33 deaths per 1000 reported in the 2003 to 31 deaths per 1000 reported in the 2008. The recorded decline of the infant and child mortality is an indicator of progress in achieving the fourth millennium development goal. Addressing challenges associated with newborn deaths in Kenya has the greatest potential of contributing to this progress. Low birth weight defined as less than $2500 \mathrm{~g}$ is one of the biggest risk factors associated with neonatal deaths. Low birth weight babies may face serious health problems as newborns and are at increased risk of long-term disabilities. Researchers trail population trends in birth weight, assuming these to have implications for infant mortality trends; [10]. In the United States of America, interventions to increase birth weight are recommended as a strategy to improve infant mortality, recommendations on
Progress towards achieving the 1990 objectives for pregnancy and infant health. [15]. There is an absence of data to explain the way in which low birth weight, small for gestational age, and preterm risks interact with neonatal mortality in high mortality burden settings. In the United States, where the neonatal mortality rate is relatively low at five per 1,000 live births, [24], mortality outcomes are reported to vary across groups of weight for gestational age, [14], with newborns born small for gestational age at 34-36 week gestation estimated to have a neonatal mortality risk as much as 44 times higher than the risk experienced by newborns with appropriate weight for gestational age, [16], [4]. There are multiple causes of low birth weight, including early induction of labour or caesarean birth, multiple pregnancies, infections and chronic conditions such as diabetes and high blood pressure but the main causes are preterm birth and restricted growth in the womb resulting in babies who are referred to as "small for their dates"; [21]. Premature birth is the primary cause of Low Birth Weight and it describes babies born before 37 completed weeks of gestation. The earlier a baby is born, the more likely it will weigh less. This is because the baby has less time in the mother's uterus to grow and gain weight [2].

Pregnancy at extreme of reproductive age, both young teenagers and older women (after 40 years), are at high risk for giving birth to low birth weight babies, [1]. His results of multivariate analysis showed a U-shaped relationship between maternal age and Low Birth Weight among whites, with the youngest (younger than 15) and the oldest (aged 40 and older) mothers being at high risk than 25-29 years old; older teenagers were not at any significantly higher risk. The consequences of low birth weight include fetal and neonatal mortality and morbidity, poor cognitive development and an increased risk of chronic diseases later in life; [10]. The contribution of low birth weight to neonatal morbidity and mortality in Kenya cannot be ignored. Neonatal intensive care is not readily available because of its initial and running costs and where available the bed capacity is extremely low. Large rural district hospitals including those with pediatricians are poorly equipped to provide essential services to sick newborns and hence the need to implement simple, cost-effective and sustainable interventions to care for the special needs of newborns, [12]. The need to focus on how to increase access to cost effective interventions that include control of the quality of infants born so as to decrease the burden and adopting simple strategies for the management of the high risk new born have been proposed, [23]. Providing local solutions to public health problems have been found to be more acceptable and more likely to be implemented.

\section{Methodology}

Models

First univariate logistic regression was performed to select potential covariates for the multiple regression models. Covariates that were significant were considered as candidate variables for multiple regression models. Cross tabulations between categorical covariates and categorized birth weight $(\backslash>$ 
$2.5 \mathrm{~kg}$ or $\backslash>=2.5 \mathrm{~kg}$ ) and child size at birth was done to have percentage distributions of low birth weight and size at birth per covariate categories. The histogram of birth weight in kilograms was plotted to see the plausibility of Gaussian model.

The following multiple variable hierarchical model was fitted in $\mathrm{R}$

$$
g(\mu)=\mathrm{X} \beta+\mu_{i}
$$

Where $g$ is the link function linking the mean of the response to the predictor

$\mathrm{X} \beta+\mu_{i}$ and $\mu_{i}$ is the area level random effect representing unmeasured contextual factors. In case of child birth weight as a response, the link function will be the identity link resulting in the Gaussian regression model. For the child size at birth as the response, the link function was the log of odds of less than average size at birth resulting in the binary logistic model. To take a more flexible approach, the continuous covariates and the area level random effects was modeled by the nonlinear smooth functions. This revealed their subtle influences which could not be shown if modeled parametrically. To reflect this flexible approach, (1) was changed to a geo-additive model

$$
\begin{aligned}
& g(\mu)=\omega_{i}^{T} \gamma+f_{1}\left(x_{i 1}\right)+f_{2}\left(x_{i 2}\right)+\ldots \ldots \\
& +f_{p}\left(x_{i p}\right)+f_{s p a t}\left(s_{i}\right)
\end{aligned}
$$

where $f_{j}$ for $\mathrm{j}=1,2,3, \ldots ., \mathrm{p}$ are smooth functions expressing non linear relationship betweeen the response variable and the continuous covariate and $f_{\text {spat }}\left(s_{i}\right)$ is the area of the child random effect. The vector of coefficients $\gamma$ determine the parametric relationship between the response and the categorical covariates. The smooth functions

$f_{j}$ was specified as Bayesian splines. This assumes approximating $f_{j}$ by the polynomial spline of degree 1 defined at equally spaced knots, [13]

$x_{i}^{\min }=\xi_{j 0}+\xi_{j 1}+. .+\xi_{j s}=x_{j}^{\max }$ Which are within the domain of the covariate $x j$. The Bayesian spline can be written as a linear combination of $\mathrm{d}=\mathrm{s}+1$ basis functions, $\mathrm{Bm}$, that is,

$$
f_{i}\left(x_{i}\right)=\sum_{m=1}^{d} \xi \beta\left(x_{j}\right)
$$

Now Bayesian estimation of the penalized spline (3) is equivalent in estimating model parameters

$$
x i_{j}=\left(\xi_{j 1}, \xi_{j 2}, \ldots \xi_{j m}\right)
$$

where first or second order random walk priors for the regression coefficients are assigned. A first order random walk prior for equidistant knots is given by:

$\boldsymbol{\xi}_{j m}=\boldsymbol{\xi}_{j, m-1}+\boldsymbol{\xi}_{j, m}$ where $\mathrm{m}=2,3, \ldots \mathrm{d}$ and a second order random walk prior for equidistant knots is given by: $x i_{j m}=2 \xi_{j, m-1}+\xi_{j, m-2}+\mu_{j . m}$ where $\mathrm{m}=3,4, \ldots, \mathrm{d}$ and $\mu_{j . m} \sim N\left(0, \tau_{j}^{2}\right)$ are random errors. The spatial effect was modeled by the tensor product of two dimensional p-spline defined as

$$
f_{\text {spat }}\left(x_{1} x_{2}\right)=\sum_{i}^{k} \sum_{j}^{k} \beta_{\text {spat }, i j} \beta_{1 i}\left(x_{1}\right) \beta_{2 j}\left(x_{2}\right)
$$

Where $\left(x_{1} x_{2}\right)$ refers to the coordinates of the location of the data point, latitude and longitude, or location centroids based on the map. Note that

$f_{\text {spat }}\left(x_{1} x_{2}\right)$ represents the effect of correlated unmeasured or unobserved location effects. The prior for

$$
\beta_{\text {spat }, j j}=\left(\beta_{\text {spat }, 11}, \beta_{\text {spat }, 12}, . ., \beta_{\text {spat }, k k}\right) \text { is based on }
$$

spatial smoothness priors common in spatial statistics

[3] The most commonly used prior specification based on the four nearest neighbours was defined as: $\left(\beta_{s p a t, i j}\right) \sim$

$$
N\left(\beta_{\text {spat }, i-1, j}+\beta_{\text {spat }, i+1, j}+\beta_{\text {spat }, i, j-1}+\beta_{\text {spat }, i, j+1,} \tau_{i j}^{2}\right)
$$

For $\mathrm{i}, \mathrm{j}=2, \ldots, \mathrm{k}-1$ with appropriate changes for corners and edges. Since model estimation will be by empirical Bayesian method, all variance parameters will be treated as unknown constants that will be estimated by restricted maximum likelihood (REML) method and hence their priors will not be given. The fixed effects was assigned diffuse priors. An advantage of the empirical Bayesian inference over full Bayesian inference is that questions about the convergence of Markov Chain Monte Carlo (MCMC) samples or sensitivity on hyper parameters do not arise [9].

Further more, a comparison of full Bayesian and empirical Bayesian approach in a simulation study, has shown empirical Bayesian approach yielding better point estimates, especially for Bernoulli distributed responses [5].

\section{Results and Discussion}

\subsection{Introduction}

The data used are from the 2014 Kenya Demographic and Health Surveys. The DHS collect information on a nationally representative sample of women in child-bearing age (15-49). The questionnaire collects socioeconomic indicators for the respondent and her partner as well as the household she resides in, and then gathers a large amount of information on fertility patterns, health and care practices, health knowledge, and assesses the anthropometric status of all children of these women who were born within the past five years.

\subsection{Descriptive Summaries}

The percentage of low birth weight infants is higher among young mothers (aged 20 years or less) and in older mothers (aged 35 to 49 years) than in mothers aged 20 to 34 years (Table 1). The inverse relationship is also observed among 
wealth quintile. As education and household wealth increases, the percentage of low birth infants decreases. For instance, the percentage of low birth weight decreases from 9.4 percent among mothers with no education to 6.5 percent among mothers with more than secondary education. Likewise percentage of births in which infants weigh less than $2.5 \mathrm{~kg}$ decreases from 8.5 percent among mothers in the lowest wealth quintile to 7 percent among mothers in the highest quintile. Among the regions (Table. 2) Nyanza region has the smallest proportion of low birth weight infants and the coastal region has the highest (3.5 and 12.7 percent respectively). Similar patterns in education and wealth quintile are seen for births categorized as very small and smaller than average as was seen for births less than $2.5 \mathrm{~kg}$.

To check the suitability of a Gaussian model, a histogram of birth weight was plotted. Fig 1 gives the histogram of birth weight in grams. The histogram show that birth weight is symmetrically distributed. This leads to a simpler model and analysis since the Gaussian assumption is more tenable.

Table 1. Distribution of birth weight and child size at birth.

\begin{tabular}{|c|c|c|c|c|}
\hline variable & Birth weight less than $2.5 \mathrm{~kg}$ & Childsize very small & smallerthan average & Average or larger \\
\hline \multicolumn{5}{|l|}{ Mother's age at birth } \\
\hline$<20$ & 9 & 3.5 & 12.4 & 82 \\
\hline $20-34$ & 7 & 3.1 & 11.3 & 84.1 \\
\hline $35-49$ & 9.4 & 4.1 & 12.6 & 81.8 \\
\hline \multicolumn{5}{|l|}{ Birth order } \\
\hline 1 & 9.4 & 3.6 & 13.9 & 81.4 \\
\hline $2--3$ & 6.5 & 2.3 & 10.6 & 85.8 \\
\hline $6+$ & 8.9 & 4.7 & 12.3 & 80.4 \\
\hline \multicolumn{5}{|l|}{$\begin{array}{l}\text { Mother's smoking } \\
\text { status }\end{array}$} \\
\hline $\begin{array}{l}\text { Smokes cigarettes/ } \\
\text { tobacco }\end{array}$ & & 12.2 & 15.6 & 72.1 \\
\hline Does not smoke & 7.6 & 3.3 & 11.6 & 83.6 \\
\hline \multicolumn{5}{|l|}{ Mother's education } \\
\hline No education & 9.4 & 5.5 & 14.4 & 76.3 \\
\hline Primary complete & 7.8 & 3.4 & 12.1 & 83.5 \\
\hline Secondary + & 6.5 & 2.3 & 11.5 & 85.7 \\
\hline \multicolumn{5}{|l|}{ Wealth quintile } \\
\hline Lowest & 8.5 & 3.5 & 11.7 & 81.9 \\
\hline Second & 5.7 & 3.3 & 10.2 & 85.3 \\
\hline Middle & 8 & 3 & 11.7 & 83 \\
\hline Fourth & 8.8 & 3.1 & 13.6 & 82.7 \\
\hline Highest & 7 & 3.5 & 11.2 & 85 \\
\hline
\end{tabular}

Table 2. Region percentage Distribution of birth weight and child size at birth

\begin{tabular}{|c|c|c|c|c|}
\hline & Birth weight & size of the child & & \\
\hline & less than $2.5 \mathrm{~kg}$ & very small & smaller than average & Average or larger \\
\hline \multicolumn{5}{|l|}{ Region } \\
\hline Coast & 12.7 & 5.3 & 13.2 & 80.5 \\
\hline North Eastern & 7.9 & 11.3 & 13.5 & 65.6 \\
\hline Eastern & 8.4 & 2.6 & 15.4 & 81.2 \\
\hline Central & 9.2 & 3.1 & 17.5 & 79.1 \\
\hline Rift Valley & 6.6 & 3.1 & 11.4 & 84.7 \\
\hline Western & 4.8 & 3.4 & 8.5 & 87.5 \\
\hline Nyanza & 3.5 & 1.8 & 6.3 & 88.5 \\
\hline Nairobi & 8.9 & 2.3 & 11.4 & 84.4 \\
\hline
\end{tabular}

\subsection{Empirical Bayesian}

\subsubsection{Fixed Effect}

Fixed variables associated with child birth weight under the Gaussian model are birth order, mother weight, and mother height (Table 3 ). The birth order effects are positive which means children with higher birth order are associated with higher child birth weight than children of lower birth order. Positive effect of mother weight means that as mother weight increase child birth weight also increase. The positive effect for mother height means that the taller the mother the higher the child birth weight as well. Factors associated with child size at birth under binary logistic model are birth order 2-3 and 4-5, wealth index of richer family, mother education of secondary category, and mother height (Table 3). The effects of birth order 2-3 and 4-5 are negative which means children of birth order 2-3 and 4-5 are associated with lower risk of being small at birth compared to those with first birth order. Mother secondary education has a negative effect on child size at birth which means children of secondary. 
Table 3. Gaussian and Logistic Results.

\begin{tabular}{lll}
\hline Variable & Logistic Coefficient(95\%CI) & Gaussian Coefficient(95\%CI) \\
\hline Intercept & $-0.481(-1.0020 .039)$ & $2.851(2.6453 .058)$ \\
Birth order & - & - \\
1 & $-0.351^{*}(-0.657-0.42)$ & $-0.105^{*}(0.040 .196)$ \\
2 to 3 & $-0.530 *(-0.951-0.128)$ & $0.138^{*}(0.018-0.259)$ \\
4 to 5 & $-0.407(-0.9010 .090)$ & $0.166^{*}(0.017-0.313)$ \\
$6+$ & & - \\
Weight & - & $0.162 *(0.0640 .263)$ \\
$<45 \mathrm{~kg}$ & $-0.262(-0.5470 .023)$ & $0.214 *(0.0650 .363)$ \\
45 to $70 \mathrm{~kg}$ & $-0.261(-0.7740 .251)$ & \\
$>70 \mathrm{~kg}$ & & - \\
Mother's education & - & $-0.004(-0.0910 .082)$ \\
No education & $-0.201(-0.4500 .048)$ & $-0.20(-0.1320 .090)$ \\
Primary & $-0.397(-0.7890 .017)$ & $-0.160(-0.4660 .146)$ \\
Secondary & $-0.702(-2.1940 .793)$ & - \\
Higher & & $0.059(0.0280 .146)$ \\
Wealth quintile & - & $0.027(0.0580 .112)$ \\
Poorest & $-0.152(-0.4130 .112)$ & $0.047(-0.0400 .134)$ \\
Poor & $-0.226(0.4930 .0044)$ & $0.056(-0.0390 .152)$ \\
Rich & $-0.340 *(-0.6320 .048)$ & - \\
Richer & $-0.301(-0.6430 .040)$ & $0.126 *(0.0440 .208)$ \\
Richest & - & 0.0226 \\
Height & $-0.500^{*}(-0.7410 .260)$ & 0.0000 \\
$<150$ & 0.6185 & 0.0003 \\
$>150$ & 0.0015 & \\
Spatial & 0.0016 & \\
Non -linear effects & & \\
Prenatal visits & & \\
Mother age & & \\
\hline
\end{tabular}

-means reference category

*means significant at 5\% significance level

Negative effect of mother height on child birth size means that children of mothers whose height is equal to or greater than $150 \mathrm{~cm}$ are less likely to be smaller than average size at birth than children of mothers whose height is less than $150 \mathrm{~cm}$.

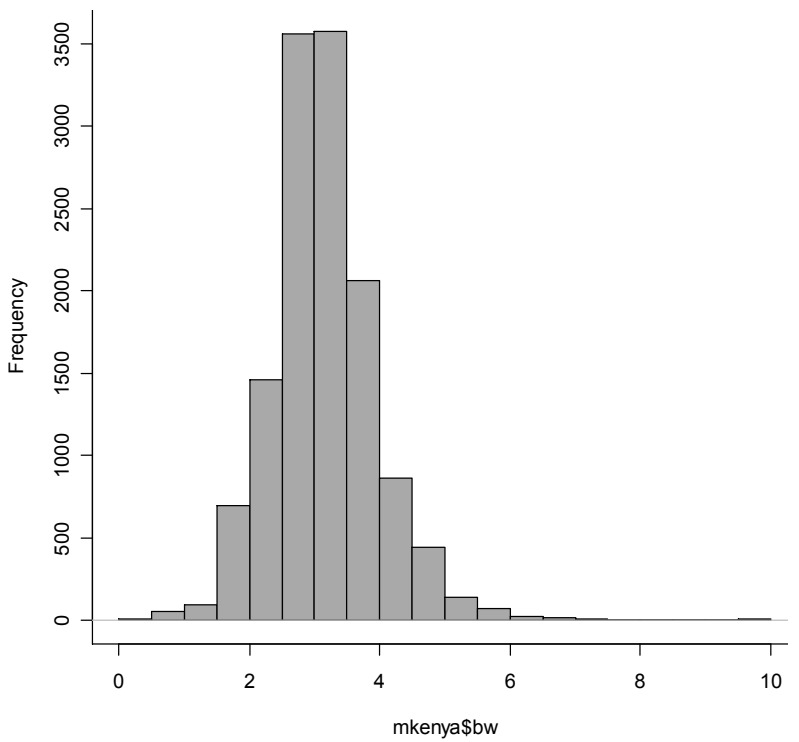

Figure 1. Histogram of Birth weight in Grams.

\subsubsection{Nonlinear Effects}

Starting with the nonlinear effects to child birth weight (Fig 2 left), children of young mothers (aged 15 to 23 years) and older mothers (aged 35 to 49 years) are more likely to have low birth weight than children of mothers aged 23 to 35 years. These results are in line with the [19]. Furthermore as number of antenatal visits for pregnancy increase, child birth weight also increases. With regard to nonlinear effects to child size at birth (Fig 2 right), children of mothers aged 15 to 25 years and children of mothers aged 35 to 49 years are prone to have small size at birth than children of mothers aged 25 to 35 years. Children whose mothers have less prenatal visits are prone to be small at birth. The study has found that, women at the reproductive ages of 25 years or less and 35 years and over are more prone to deliver low birth weight or small sized babies. (Fig 2 top left and Fig 2 top right). Mothers less than 25 years are actually prone to have physical and emotional maturity issues which may contribute to their elevated incidence of small size births or low birth weight infants. Their ignorance of how to take care of themselves during pregnancy works against child birth weight or size at birth. Accordingly, among mothers who are 35 years or older, there is a greater tendency to develop prenatal complications and a higher probability of inadequate nutrition, thus increasing their likelihood of delivering less than average size or low birth weight babies. The study has further shown that mothers whose prenatal visits are less than four are prone to have low birth weight or less than average size babies (Fig. 2 bottom left and Fig. 2 bottom right). Increased prenatal visits ensure mothers receive adequate diet literacy which helps improve child birth weight. 

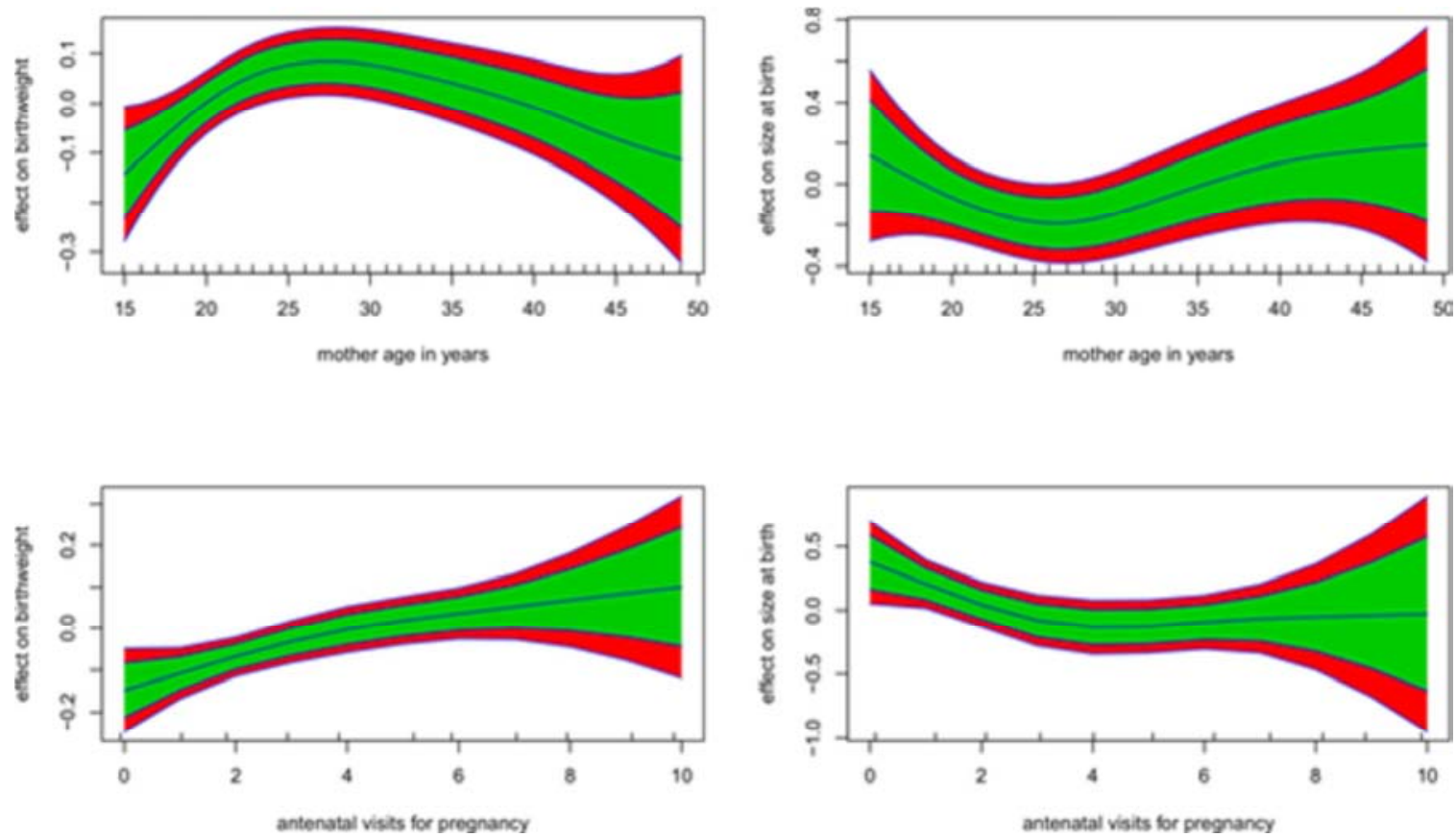

Figure 2. Nonlinear terms from the Gaussian and logistic model (left and right).

\subsubsection{Spatial Effects}

Spatial statistics extends traditional statistics to support the analysis of geographic data. It provides techniques to describe the distribution of data in the geographic space (descriptive spatial statistics),analyze the spatial patterns of the data (spatial pattern analysis), identify and measure spatial relationships (spatial regression), and create a surface from sampled data.

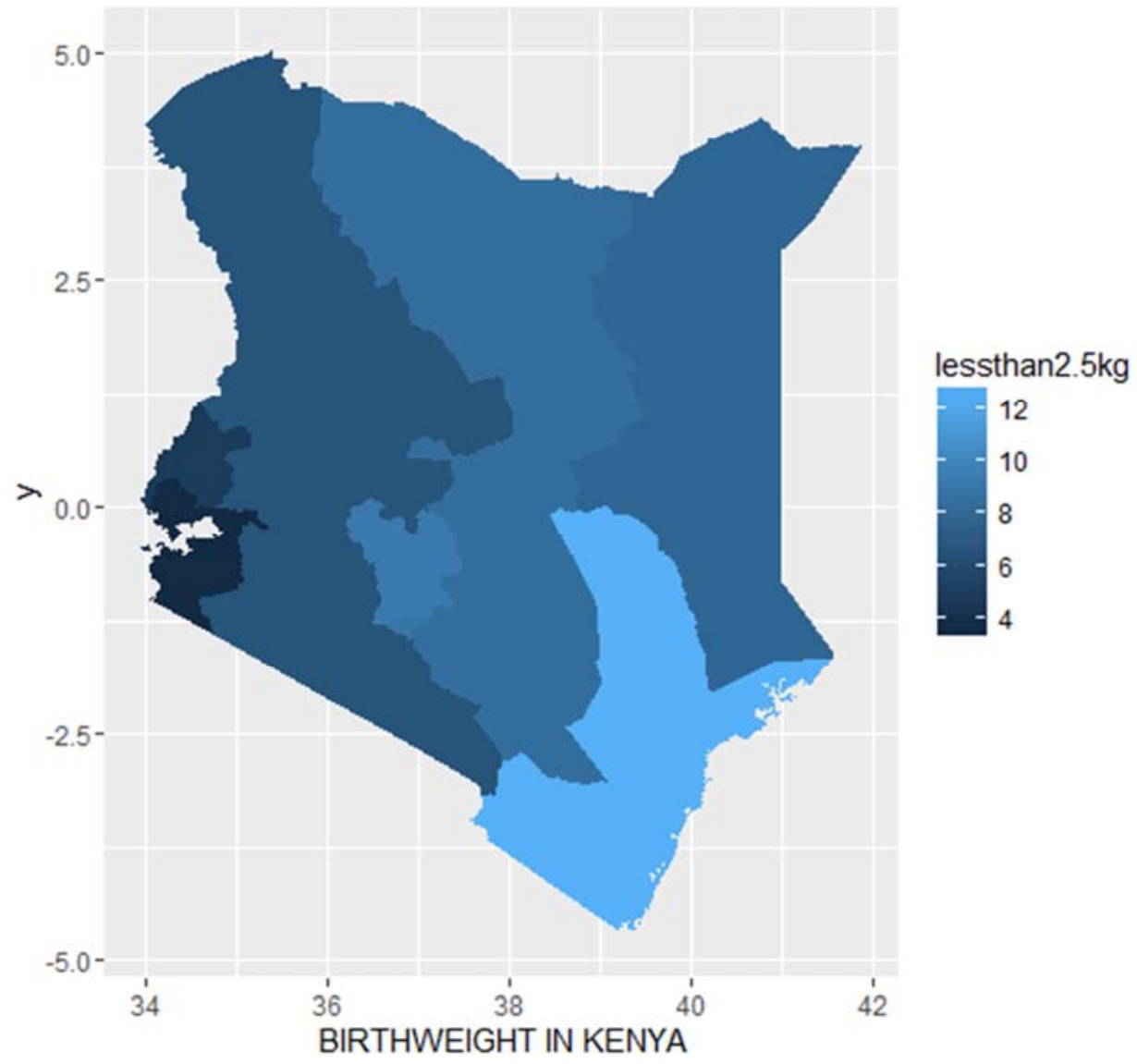

Figure 3. Distribution of Birth weight in Kenya. 
(a) Descriptive Spatial Analysis

Nyanza province has a higher percent of weight normal birth (greater than $2.5 \mathrm{Kg}$ ), followed by Western and Rift valley (Fig. 3). Nairobi, Central and coast regions are associated by decreasing birth weight. With regard to child size at birth, Nyanza has the lowest percentage of very small size, followed by Nairobi, Eastern and North Eastern has the largest percent. (Fig. 4) and (Fig. 5).

(b) Spatial Regression Analysis

Figure 7 presents total residual spatial effects to child size at birth. North Eastern, Eastern, Coast, Western and Nyanza are associated with increased risk of child being small at birth(positive effects) while Rift valley and central are associated with decreased(negative effect) risk of child being small at birth. Rift valley and Western are associated with increased birth weight (Fig. 6) while coast and central provinces have a decreasing birth weight. The observed residual spatial heterogeneity may be due to unobserved factors not captured by the covariates in the models, and it is a matter of conjecture to identify them. Regional nutritional disparities may also explain the spatial heterogeneity of low birth weight.

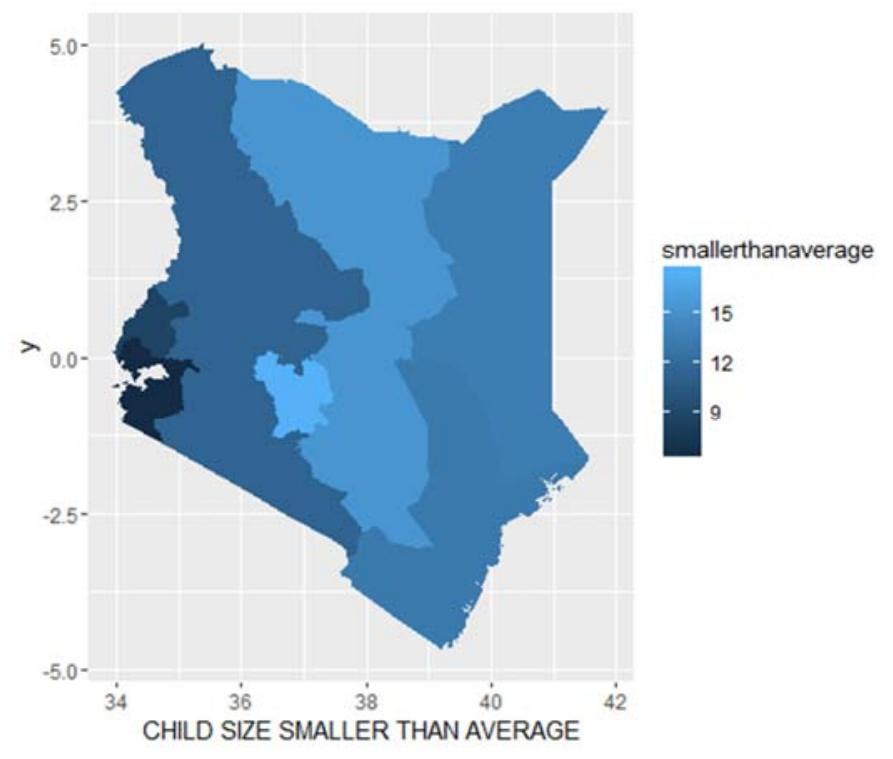

Figure 4. Child size Smaller than Average in Kenya.

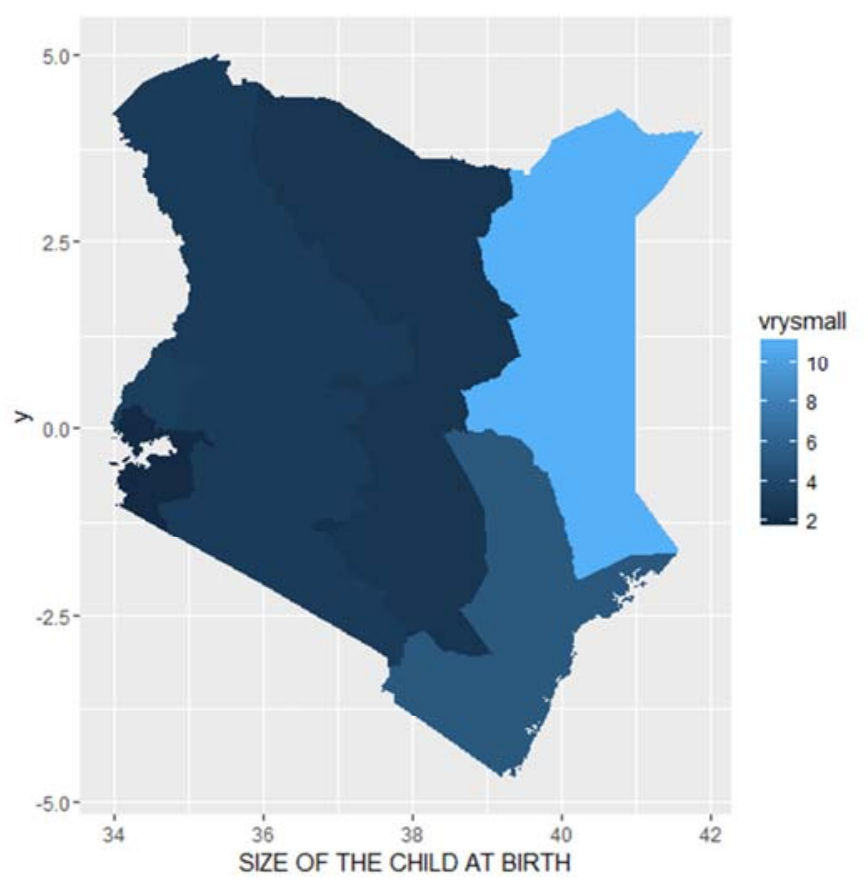

Figure 5. Child size at birth Very Small in Kenya. 
The cause of regional nutritional differences can be natural disasters like floods, and varying climatic conditions. This study employed the use of geo-additive logistic model to study the relationship between birth weight and its risk factors. The geo-additive model allowed the mapping of residual spatial effects to child size and birth weight while accounting for non-linear covariate effects under the assumption of additiviness. This study found that child birth order, mother weight, mother height, mother education and family wealth are significant predictors of birth weight. The study is in consistent with the findings of the previous study done by, [11]. The positive effect of mother's education on birth weight in this study is in consistent with other studies, [22], [20] which found mother education as an important factor influencing birth weight. The finding of a positive effect of mother weight, and height on birth weight is also in line with, [6], [18], where they concluded that, such a relationship is because mother weight and height reflect food taken which has a direct influence on child birth weight. The mechanisms associated with small size at birth among the less educated, may include poor diet as a result of low dietary literacy [20]. Furthermore limited education may also result in limited access to prenatal care, especially in settings where clients are expected to pay for service. Positive effect of family wealth on child birth weight may be due to the fact that wealth is associated with income level which determines kind of diet.

The study has also documented that women at the reproductive ages of 25 years or less and 35 years and over are more prone to deliver low birth weight or small sized babies (Fig 2 top left and Fig 2 top right). Mothers less than 25 years are actually prone to have physical andemotional maturity issues which may contribute to their elevated incidence of small size births or low birth weight infants. Their ignorance of how to take care of themselves during pregnancy works against child birth weight or size at birth. Accordingly, among mothers who are 35 years or older, there is a greater tendency to develop prenatal complications and a higher probability of inadequate nutrition, thus increasing their likelihood of delivering less than average size or low birth weight babies. The study has further shown that mothers whose prenatal visits are less than four are prone to have lowbirth weight or less than average size babies (Fig 2 bottom left and Fig 2 bottom right). Increased prenatal visits ensure mothers receive adequate diet literacy which helps improve child birth weight.

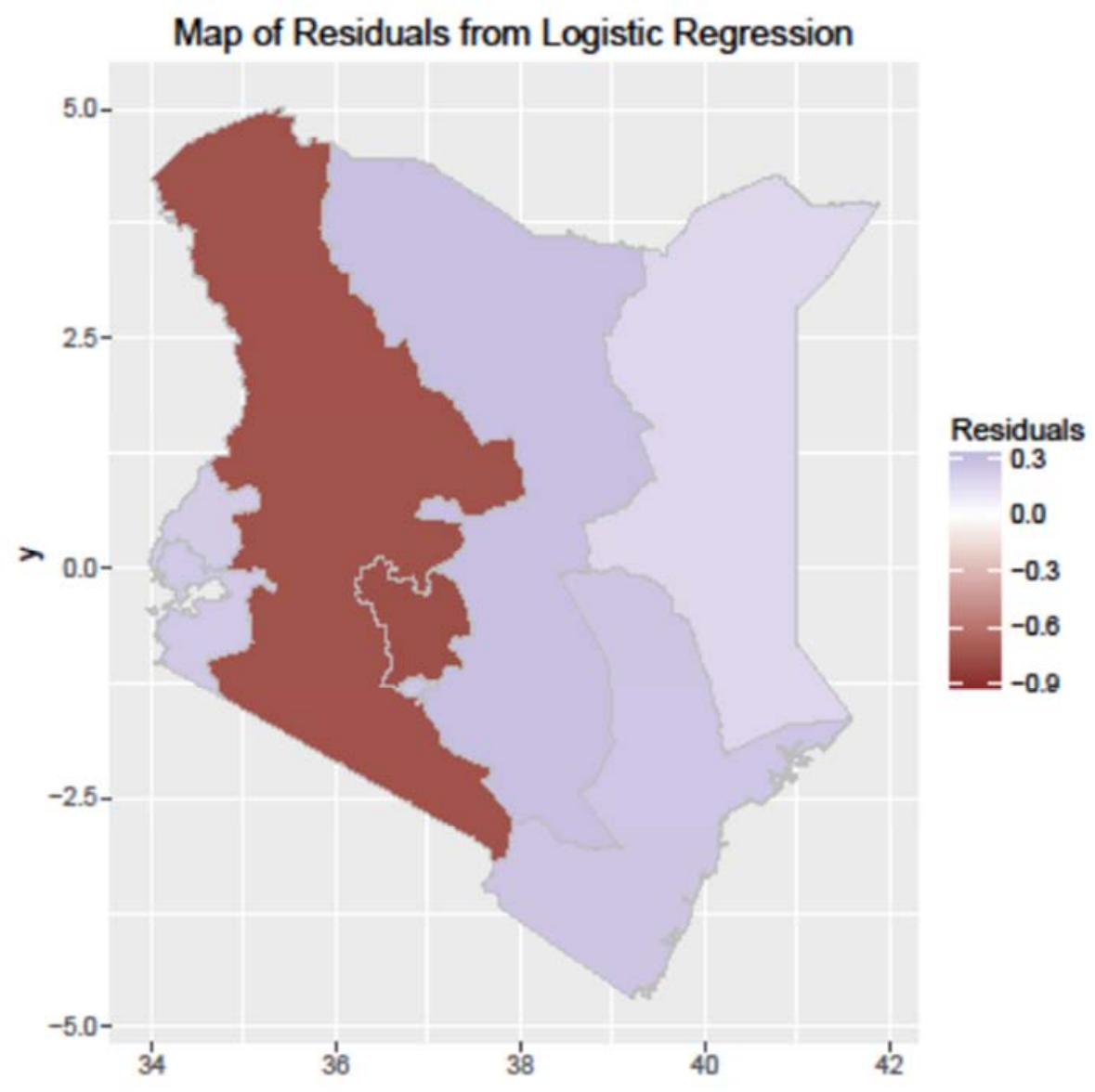

Figure 6. Residual spatial patterns from the logistic model.

The study was not without weaknesses. Due to the cross-sectional nature of the data collection exercise, no temporal linkages can be made between birth weight or size at birth and any of the explanatory variables. Moreover, because the analysis was based on an existing data set, the study was limited to the use of variables found in the data set. 


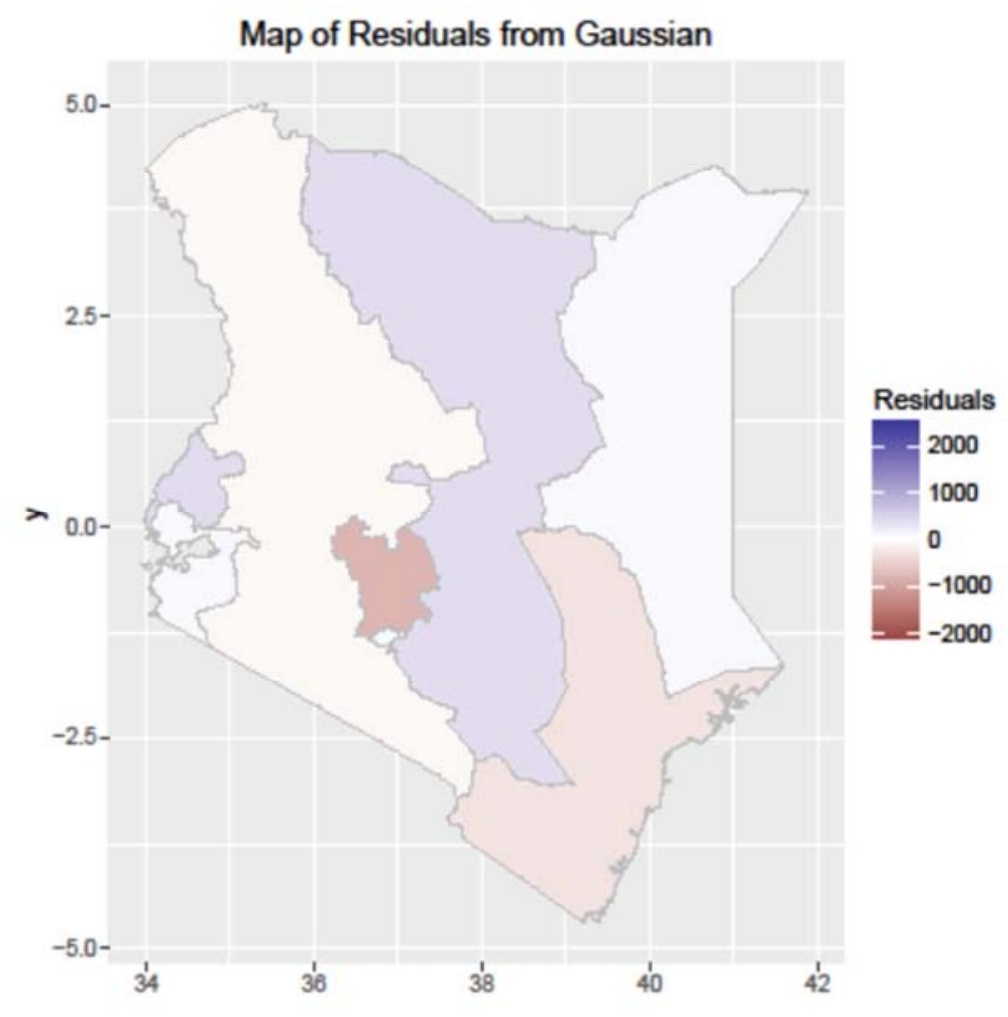

Figure 7. Residual spatial patterns from the Gaussian model.

\section{Conclusions and Recommendations}

\subsection{Conclusions}

In this study we pooled the data from the 2014 demographic and Health surveys of Kenya to model the socio-demographic and spatial determinants of Low birth weight. The study found strong support for our approach of flexibly modeling some covariates that clearly have non-linear influences and for including a spatial analysis. The spatial effect of the low birth weight outcomes appeared weak across the various regions. The spatial analysis shows distinct spatial patterns that point to the influence of omitted variables with a strong spatial structure or possibly epidemiological processes that account for this spatial structure.

The maps generated could be used for targeting development efforts at a glance, or for exploring relationships between welfare indicators and others variables. For example, birth weight less than $2.5 \mathrm{Kg}$ map could be overlaid with maps of other types of data, say on size of birth very small. The visual nature of the maps may highlight unexpected relationships that would be overlooked in a standard regression analysis

\subsection{Recommendations}

We recommend that future related studies involving various adverse birth weight outcomes be traced at district level. This will enable minimal mismatch between risk factors and the low birth weight.

\section{Acknowledgments}

I am most grateful to Almighty God who through His infinite mercy and love guided me throughout the duration of writing this Project report. This work has been accomplished with the assistance of many people who deserve special mention for their support. My deep appreciation goes to my supervisor Dr. Anthony Wanjoya and Dr. Levi Mbugua who constantly told me it could be done and prompted me to continue when I had lost hope. I am particularly inspired by their dedication in seeing this work through. To them I say many thanks and God bless.

\section{References}

[1] Aras R Y (2013). Is maternal age risk factor for low birth weight ?Arch med Health Sci 1: 33-7.

[2] Back, W, (2010). Low Birth Weight. March of Dimes, Professionals and Researchers. Available at; http://www.marchofdimes.com/professionals/14332-1153.asp Accessed on February 2016.

[3] Besag J, Kooperberg C. (1995) On Conditional and Intrinsic autoregression. Biometrika., 82: 733-746. doi: $10.2307 / 2337341$.

[4] Copper RL, Goldenberg RL, Creasy RK, DuBard MB, Davis RO, (1993) A multicenter study of preterm birth weight and gestational age-specific neonatal mortality. 168: 78-84. 
[5] Fahrmeir L, Kneib T, Lang S.(2004). Penalized structured additive regression for space-time data: a Bayesian perspective. Statistica Sinica.; 14: 731-761.

[6] Kader M, Tripathi N (2013) Determinants of low birth weight in rural Bangladesh, Int J Reprod Contracept Obstet Gynecol. 2 (2): 130-134.

[7] Kenya Demographic and Health Survey 2008-09 (2009). Child Health; Weight and size at birth. Available http://www.measuresdhs.com/pubs/pdf/FR229/FR229.pdf.

[8] Kenya National Bureau of Statistics (KNBS) and ICF Macro (2010). Kenya Demographic and Health Survey 2008-09. Calverton, Maryland.

[9] Kneib T, Lang S, Brezger A.(2004) Bayesian semiparametric regression based on mixed model methodology: A tutorial. Munick. University of Munich.

[10] Mittendorf R, Herschel M, Williams MA, Hibbard JU, Moawad AH, Lee K(1994). Reducing the frequency of low birth weight in the United States. Obstet Gynecol vol. 83: 1056-105.

[11] Ngwira A, Stanley CC (2015) Determinants of Low Birth Weight in Malawi: Bayesian Geo-Additive Modelling. PLoS ONE 10 (6): e0130057. doi: 10.1371/journal. pone.0130057.

[12] Opondo C, Ntoburi S, Wagai J, Wafula J, Wassuna A, Were F, et.al(2009). Are hospitals prepared to support newborn survival?-an evaluation of eight first- level hospitals in Kenya. Tropical Medicine and International Health. 14 (10): 1165-72.

[13] Osei FB, Duker AA, Stern A. (2012)Bayesian structured additive regression modeling of epidemic cholera data: application to cholera. Medical Research Methodology. doi: 10.1186/1471-2288-12-118. pmid:22866662.

[14] Parker J D, Klebanoff M A (2009) Invited commentary: Crossing curves-it's time to focus on gestational age-specific mortality. Am J Epidemiol 169: 798-801. doi: 10.1093/aje/kwp025.

[15] Public Health Service (1998). Progress toward achieving the 1990 objectives for pregnancy and infant health. 37: 405-12.

[16] Pulver LS, Guest-Warnick G, Stoddard GJ, Byington CL, Young PC (2009) Weight for gestational age affects the mortality of late preterm infants. Pediatrics 123: e1072-e1077. doi: $10.1542 /$ peds.2008-3288.
[17] Resolution WHA65.6. Comprehensive implementation plan on maternal, infant and young child nutrition. In: Sixty-fifth World Health Assembly Geneva, 21-26 May 2012. Resolutions and decisions, annexes. Geneva: World Health Organization; 2012: 12-13 (http://www.who.int/nutrition/topics/accessed 17 October 2015).

[18] Rode L, Hegaard HK, Kjaergaard H, Møller LF, Tabor A, Ottesen B.(2007). Association between maternal weight gain and birth weight. pubmed. 09 (6): 1309-15.

[19] Roth, J., \& Hendrickson, J. (1998). The risk of teen mothers having low birth weight babies: Implications of recent medical research. Journal of School Health, 68 (7), 271.

[20] Stewart PJ, Potter J, Dulberg C, Niday P, Nimrod C. Tawagi G.(1995) Change in smoking prevalence among pregnant women 1982-93. Can J Public Health vol. 86: 37-41.

[21] United Nations Children's Fund and World Health Organization, (2004) Low Birthweight: Country, regional and global estimates. UNICEF, New York.

[22] Wasunna A, Mohammed K (2002) Low birth weight babies: socio demographic and obstetric characteristics of adolescent mothers at Kenyatta National Hospital, Nairobi. East Afr Med J.79: 543-546.

[23] Were FN, Mukhwana BO, Musoke RN(2002). Neonatal survival of infants less than $2000 \mathrm{~g}$ born at Kenyatta National Hospital. East African Medical Journal.;79 (2): 77-9.

[24] World Health Organization (2004) Department of Reproductive Health and Research Avenue Appia 20, 1211 Geneva 27, Switzerland reproductive-health@who.int www.who.int.

[25] World Health Organization (2005): Low birth weight: country regional and global estimates. WHO publication.

[26] World Health Organization (2014). Global targets 2025. To improve maternal, infant and young child nutrition (www.who.int/nutrition/topics/nutrition globaltargets2025/en/, accessed 17 October 2015).

[27] World Health Organisation (2006) Neonatal and perinatal mortality: country, regional and global estimates. Available: http://whqlibdoc.who.int/publications/2006/9241563206 eng.pdf. 